\title{
Two new species of the aphid genus Uroleucon (Hemiptera: Aphididae) living on Grindelia in the USA
}

\author{
Shalva BARJADZE ${ }^{1} \&$ Mariusz KANTURSKI ${ }^{2, *}$ \\ ${ }^{1}$ Institute of Zoology, Ilia State University, Giorgi Tsereteli 3, 0162, Tbilisi 0159, Georgia. \\ ${ }^{2}$ Zoology Research Team, Institute of Biology, Biotechnology and Environmental Protection, \\ Faculty of Natural Sciences, University of Silesia in Katowice, Bankowa 9, 40-007 Katowice, Poland. \\ ${ }^{*}$ Corresponding author: mariusz.kanturski@us.edu.pl \\ ${ }^{1}$ Email: shalva.barjadze@yahoo.com \\ ${ }^{1}$ urn:1sid:zoobank.org:author:63ABE1B2-8A56-42C8-BC34-1119D3A2ECBC \\ ${ }^{2}$ urn:lsid:zoobank.org:author:78C290A3-D07B-4AF9-9358-ED8C05A702BF
}

\begin{abstract}
Here, we present descriptions of two new aphid species of the genus Uroleucon Mordvilko, 1914 (Hemiptera: Aphididae: Macrosiphini), which are associated with the plant genus Grindelia Willd. (Asteraceae). An apterous viviparous female of Uroleucon (Lambersius) robinsoni sp. nov. from Oregon and apterous and alate viviparous females of Uroleucon (Lambersius) grindeliae sp. nov. from Colorado are described and illustrated. Taxonomical notes of the new and other Grindelia-feeding taxa of Uroleucon are given and an updated key to the apterae of the Grindelia-feeding species of Uroleucon in the world is provided.
\end{abstract}

Keywords. Macrosiphini, Uroleucon, Lambersius, new taxa, North America.

Barjadze S. \& Kanturski M. 2020. Two new species of the aphid genus Uroleucon (Hemiptera: Aphididae) living on Grindelia in the USA. European Journal of Taxonomy 729: 42-53.

https://doi.org/10.5852/ejt.2020.729.1189

\section{Introduction}

The genus Uroleucon Mordvilko, 1914, which comprises 239 aphid species in the world, is one of the most speciose genera in the tribe Macrosiphini Wilson, 1910 (Favret 2020). The genus has six subgenera: Belochilum Börner, 1932 (one species), Divium Pashtshenko, 2000 (one species), Lambersius Olive, 1965 (53 species), Satula Olive, 1963 (one species), Uroleucon Mordvilko, 1914 (122 species) and Uromelan Mordvilko, 1914 (61 species) (Favret 2020). All of the species live on herbaceous plants that belong to the families Asteraceae (more than 160 species) and Campanulaceae (11 species) without any host alternation; only nine species use host plants from other plant families (Blackman 2010; Blackman \& Eastop 2020). The coloration of species of Uroleucon varies from green to blackish brown (Heie 1995; Blackman \& Eastop 2020). The genus is generally characterized by well-developed antennal tubercles with diverging inner sides, the presence of secondary rhinaria on the basal part of antennal segment III in apterae, often a very long processus terminalis, ultimate rostral segments with blunt apices, long 
and cylindrical reticulated siphunculi, a finger-shaped cauda with a pointed apex and five setae (a few species have three or four setae) on the first tarsal segments. In many species, the abdominal dorsal setae are located on pigmented scleroites (Blackman \& Eastop 2020).

During an examination of the aphid collection in the Natural History Museum of London (BMNH), slides with two undescribed species of Lambersius, which had been sampled on Grindelia hirsutula Hook. \& Arn. and G. squarrosa (Pursh) Dunal (Asteraceae) in Oregon and Colorado, respectively, were recognized. In Blackman \& Eastop (2006: 496), these species were included in the key to apterae aphids on Grindelia Willd. as "Uroleucon (Lambersius) sp. (on G. stricta DC., Oregon)" and "Uroleucon (Lambersius) sp. (on G. squarrosa, Colorado)". The aim of this paper is to describe these two Grindeliafeeding species of Lambersius from the USA.

\section{Material and methods}

The specimens were examined using a Leica DM 3000 LED light microscope and photographed using a Leica MC 190 HD camera. The measurements were taken according to Ilharco \& van Harten (1987). The measurements are given in millimeters. The material examined for each species is given in the review of the species. The host plant names are given according to the most recent edition of The Plant List (2013).

\section{Abbreviations for morphological terms used in the text}

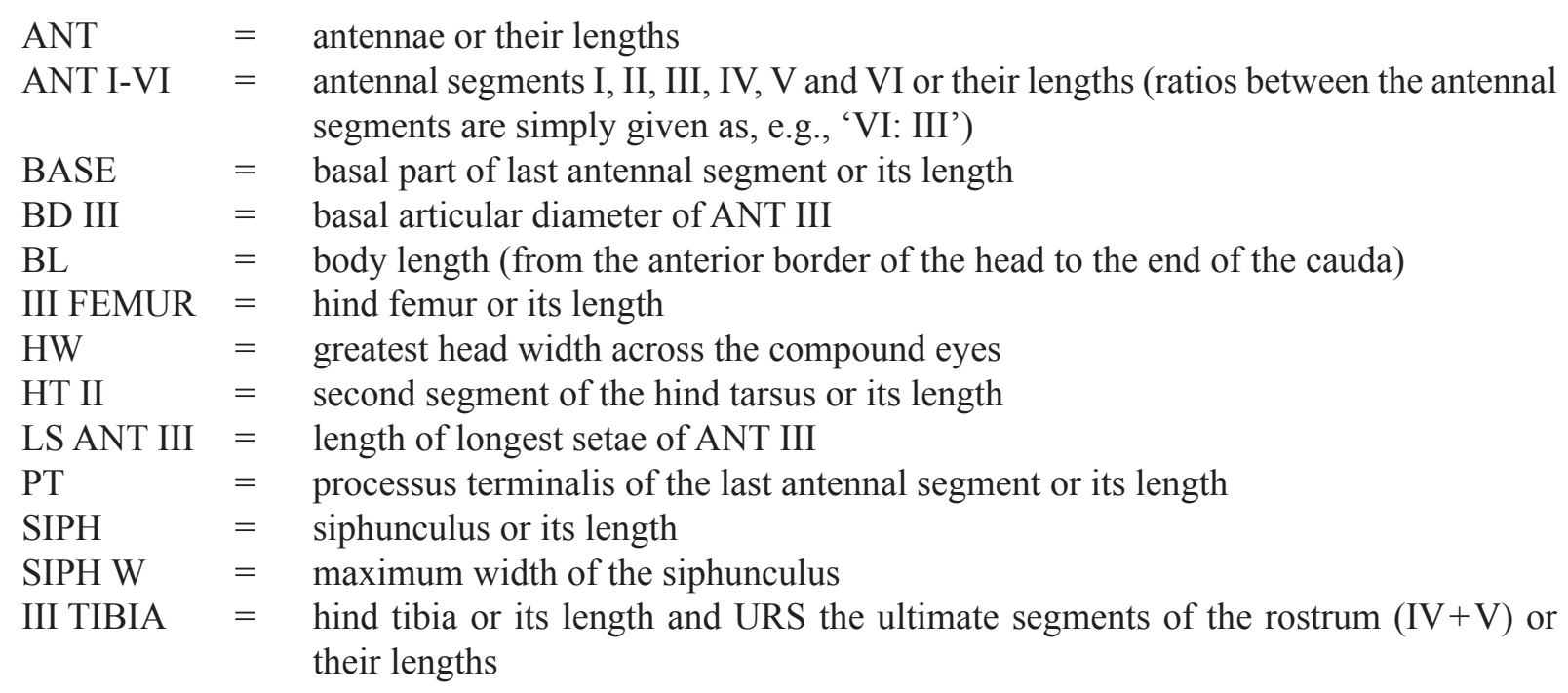

\section{Abbreviations for depositories for the type material}

NHMUK = Natural History Museum, London, UK

DZUS = Hemiptera Collection of the Department of Zoology, University of Silesia, Katowice, Poland 


\section{Results}

\section{Taxonomy}

Class Insecta Linnaeus, 1758

Order Hemiptera Linnaeus, 1758

Family Aphididae Latreille, 1802

Genus Uroleucon Mordvilko, 1914

Uroleucon (Lambersius) robinsoni sp. nov.

urn:1sid:zoobank.org:act:C7C38DD0-01C5-4BB4-9938-1D3CD3D8A81A

Figs 1-2, Table 1

\section{Diagnosis}

Apterous viviparous females of Grindelia-feeding Lambersius have the following combinations of characters: PT 4.66-6.50× BASE; ANT III with 12-21 secondary rhinaria (Fig. 2a-b); URS 1.06-

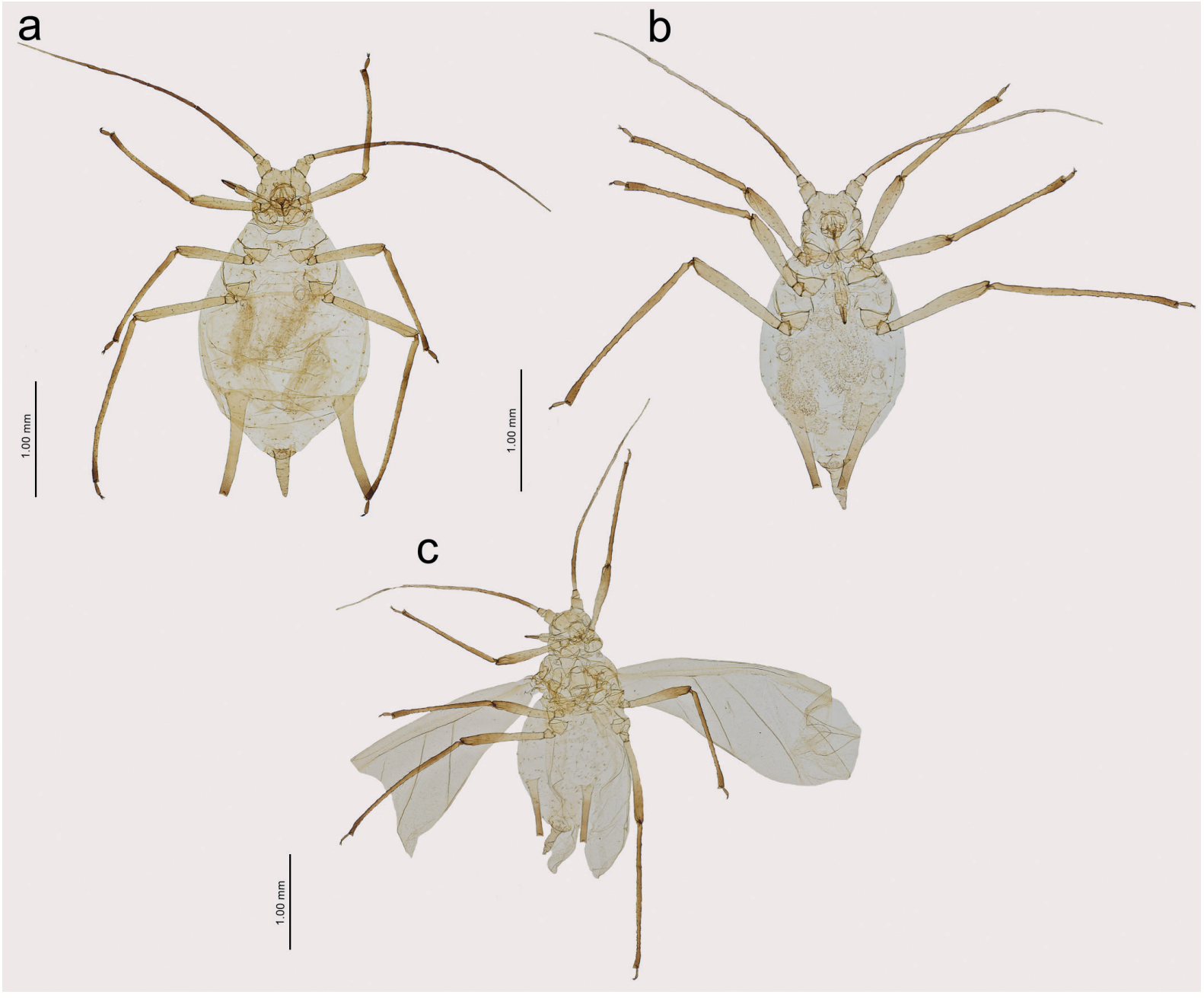

Fig. 1. New species of Uroleucon Mordvilko, 1914 feeding on Grindelia Willd. a. Uroleucon (Lambersius) robinsoni sp. nov., holotype, apterous viviparous female (NHMUK 010121495) b. U. (L.) grindeliae sp. nov., holotype, apterous viviparous female (NHMUK 010121473) c. U. (L.) grindeliae sp. nov., paratype, alate viviparous female (NHMUK 010121477). 
1.33 $\times$ BASE and 1.18-1.25 $\times$ HT II with 7-9 short, fine, pointed accessory setae (Fig. 2d); HT I with 5:5:5 setae; SIPH subcylindrical, slightly tapering without a flange (Fig. 2e); its reticulated zone 0.17$0.28 \times$ SIPH. SIPH 2.30-2.68 $\times$ cauda and $0.31-0.41 \times$ BL; scleroites on setal bases absent on ABD I-V, while setae on ABD VI-VIII arise from barely visible, rounded scleroites; cauda narrow finger-shaped without constriction and with 7-9 setae (Fig. 2f).

\section{Etymology}

We are very pleased to name the new species in honor of A.G. Robinson (University of Manitoba, Canada), who worked on the North American Macrosiphini.

\section{Material examined}

\section{Holotype}

USA $\bullet+$ apterous viviparous; Colorado, Carson Hole; 38 $8^{\circ} 43^{\prime}$ N, $108^{\circ} 36^{\prime}$ W; alt. 2348 m; 16 Sep. 1956; Hottes and Hille Ris Lambers leg.; Grindelia squarrosa; NHMUK 010121495.

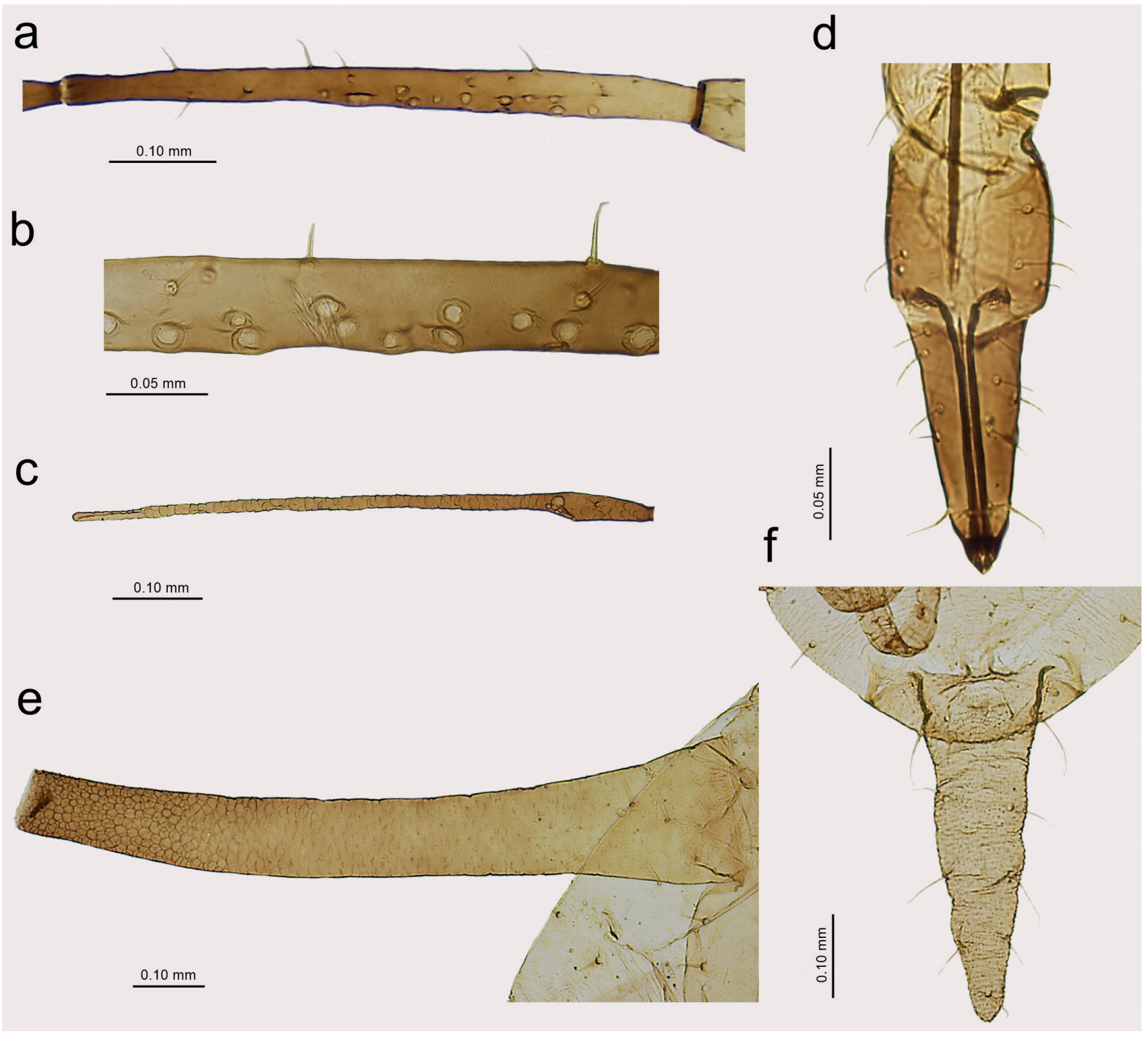

Fig. 2. Uroleucon (Lambersius) robinsoni sp. nov., holotype, apterous viviparous female (NHMUK 010121495). a. ANT III. b. Secondary rhinaria on ANT III. c. ANT VI. d. Ultimate rostral (III-V) segments. e. Siphunculus. f. Cauda. 
Table 1. Measurements of the known morphs of Uroleucon (Lambersius) robinsoni sp. nov. and $U$. (L.) grindeliae sp. nov. Measurements of the holotype are given in parentheses after the ranges.

\begin{tabular}{lccc}
\hline Character & $\begin{array}{c}\text { Uroleucon robinsoni } \\
\text { Apterous viviparous } \\
\text { female }\end{array}$ & $\begin{array}{c}\text { Uroleucon grindeliae } \\
\text { Apterous viviparous } \\
\text { female }\end{array}$ & $\begin{array}{c}\text { Alate viviparous } \\
\text { female }\end{array}$ \\
\hline BL & $2.50-3.20(2.90)$ & $2.17-3.02(2.67)$ & $2.02-2.95$ \\
HW & $0.46-0.50(0.46)$ & $0.47-0.52(0.47)$ & $0.46-0.50$ \\
ANT & $2.39-2.91(2.43)$ & $1.99-2.48(2.23)$ & $2.25-2.54$ \\
ANT III & $0.62-0.75(0.65)$ & $0.51-0.70(0.61)$ & $0.64-0.70$ \\
ANT IV & $0.45-0.57(0.46)$ & $0.37-0.47(0.41)$ & $0.42-0.50$ \\
ANT V & $0.40-0.53(0.40)$ & $0.32-0.42(0.38)$ & $0.41-0.46$ \\
ANT VI & $0.73-0.90(0.74)$ & $0.55-0.67(0.62)$ & $0.58-0.70$ \\
BASE & $0.12-0.15(0.12)$ & $0.12-0.16(0.14)$ & $0.12-0.16$ \\
PT & $0.61-0.78(0.62)$ & $0.43-0.52(0.48)$ & $0.46-0.54$ \\
URS & $0.15-0.16(0.15)$ & $0.15-0.16(0.16)$ & $0.15-0.17$ \\
FEMORA III & $0.80-0.97(0.80)$ & $0.84-1.05(0.90)$ & $0.84-0.97$ \\
TIBIAE III & $1.50-1.87(1.52)$ & $1.47-1.82(1.70)$ & $1.52-1.77$ \\
HT II & $0.12-01.3(0.12)$ & $0.12-0.13(0.12)$ & $0.11-0.12$ \\
SIPH & $0.86-1.10(0.92)$ & $0.62-0.80(0.66)$ & $0.58-0.68$ \\
CAUDA & $0.37-0.44(0.40)$ & $0.40-0.45(0.40)$ & $0.37-0.40$ \\
\hline
\end{tabular}

\section{Paratypes}

USA $・ 2$ 2 q apterous viviparous; same collection data as for holotype; NHMUK $010121495 \cdot 2$ q $q$ apterous viviparous; same collection data as for holotype; NHMUK 010121496 • 2 우 apterous viviparous; same collection data as for holotype; DZUS 010121481 2 우 우 apterous viviparous; same collection data as for holotype; NHMUK 010121482.

\section{Description}

Apterous viviparous female $(\mathrm{n}=9)$

COLOR IN LIFE. Unknown.

Pigmentation of Cleared SPECIMENS ON SLIDE. Body generally membranous, pale to yellow; ANT brown with pale ANT I-II and basal part of ANT III; coxae and trochanters pale; femora yellow with light brown distal ends; tibiae brown with paler middle section or pale with only distal part darker; tarsi light brown; SIPH yellow with light brown to brown distal ends; cauda pale (Fig. 1a).

MORPHOMETRIC CHARACTERS. HW $0.17-0.19 \times$ ANT. Head with thick, rigid setae with blunt or narrowly capitate apices, $0.030-0.040 \mathrm{~mm}$ long. ANT tubercles each with $2-3$ setae. ANT $0.83-1.04 \times$ BL. ANT III with 12-21 rounded secondary rhinaria of different sizes, with sclerotized rims (Fig. 2a-b), ANT IV longer than ANT V. PT 4.66-6.50 × BASE (Fig. 2c). Other antennal ratios: VI:III 1.13-1.28, V:III 0.610.70, IV:III 0.70-0.76, PT:III 0.93-1.11, PT:IV 1.22-1.47 and PT:V 1.32-1.69. ANT bearing medium length thick, rigid setae with blunt or narrowly capitate apices. ANT III setae $0.020-0.045 \mathrm{~mm}$ long, LS ANT III 0.84-1.13 × BD III. ANT I with 4-5, ANT II with 3-4, ANT III with 12-21, ANT IV with 8-12, ANT V with 7-9 setae. ANT VI with 3 basal, 4 apical and 2-5 setae on PT. Rostrum reaching middle coxae in some specimens to as far as hind coxae in other specimens. URS $0.21-0.24 \times$ ANT III, $0.17-0.20 \times$ ANT VI, $0.20-0.24 \times$ PT, $1.06-1.33 \times$ BASE and $1.18-1.25 \times$ HT II with $7-9$ short, fine and pointed accessory setae (Fig. 2d). Mesosternal furca fused, wide, T-shaped. Hind femora bearing 
medium length, thick, rigid setae with narrowly capitate or slightly pointed apices, $0.020-0.040 \mathrm{~mm}$ long. Hind tibiae bearing thick, rigid setae, most slightly pointed or blunt, shorter than width of tibiae, $0.025-0.045 \mathrm{~mm}$ long. In some specimens, tibiae bearing few pseudosensoria. HT I with 5:5:5 setae, HT II $0.18-0.19 \times$ ANT III, $0.14-0.16 \times$ ANT VI, $0.16-0.20 \times$ PT and $0.86-1.08 \times$ BASE. SIPH subcylindrical, slightly tapering and curved externally with distinct zone of subapical reticulation and without flange (Fig. 2e). Reticulated zone $0.17-0.28 \times$ SIPH. SIPH $2.30-2.68 \times$ cauda, $0.31-0.41 \times$ BL, and 1.38-1.57 $\times$ ANT III. Abdomen membranous with medium length, thick rigid setae with narrowly capitate or blunt apices, $0.025-0.040 \mathrm{~mm}$ long on ABD I-V and $0.030-0.040 \mathrm{~mm}$ long on ABD VIVIII. ABD VIII with 4 setae. Scleroites on setal bases absent on ABD I-V, while setae on ABD VI-VIII arising from very poorly visible, rounded and pale scleroites. Genital plate with two anterior setae longer than others, $7-10$ posterior setae. Cauda narrow finger-shaped without constriction, $2.05-2.75 \times$ its width at base and $0.13-0.15 \times$ BL with 7-9 fine setae (Fig. 2f).

\section{Remarks}

Of the six Grindelia-feeding aphids of Uroleucon, only U. penderum Robinson, 1986, U. robinsoni sp. nov. and $U$. grindeliae sp. nov. have shared characters: (1) ANT III has the majority of the secondary rhinaria on the basal half and (2) their URS/HT II ratio is 1.15 or more and (3) the coxae and trochanters are pale (Robinson 1986; Blackman \& Eastop 2020).

The apterous viviparous females of Uroleucon robinsoni sp. nov. differ from the same morphs of U. penderum: (1) their SIPH/CAUDA L ratio is 2.30-2.68 in U. robinsoni sp. nov., while it is $1.65-1.95$ in $U$. penderum, (2) their URS/HT II ratio is $1.18-1.25$ in U. robinsoni sp. nov., while it is $1.3-1.6$ in U. penderum, (3) the pigmentation of the tibiae is dusky or dark for most of their length in Uroleucon robinsoni, while their tibiae are pale except at the apices in U. penderum (Blackman \& Eastop 2020).

The apterous viviparous females of the two new species differ from each other in the following characters: (1) their ANT PT/BASE ratio is 4.66-6.50 in U. robinsoni sp. nov., while it is 3.31-3.61 in U. grindeliae sp. nov., (2) their SIPH/CAUDA ratio is 2.30-2.68, while it is 1.37-1.77 in U. grindeliae sp. nov. and (3) their cauda is finger shaped with no constriction in U. robinsoni sp. nov. (Fig. 2f), while it is tongue shaped with an evident constriction near the base in U. grindeliae sp. nov. (Fig. 3f).

\section{Biology and distribution}

The species was collected from Grindelia squarrosa in Colorado, USA. Other morphs and the life cycle of the new species are unknown.

Uroleucon (Lambersius) grindeliae sp. nov. urn:1sid:zoobank.org:act:714DE06E-C8CB-4404-8FDA-569C01524ADC

Figs 1, 3, Table 1

\section{Diagnosis}

Apterous viviparous females of Grindelia-feeding Lambersius share the following combinations of characters: PT 3.31-3.61 $\times$ BASE; ANT III with 7-16 secondary rhinaria (Fig. 3a-b); URS 1.03$1.37 \times$ BASE and 1.19-1.37 $\times$ HT II with 6-9 short, fine, pointed accessory setae (Fig. 3d); HT I with 5:5:5 setae; SIPH subcylindrical, slightly tapering without a flange (Fig. 3e); its reticulated zone 0.27$0.31 \times$ SIPH. SIPH $1.37-1.77 \times$ cauda and $0.24-0.30 \times$ BL; scleroites on setal bases absent on ABD I-V, while the setae on ABD VI-VIII arising from barely visible, rounded scleroites; cauda tongue-shaped with evident constriction near its base and with 9-12 setae (Fig. 3f). 


\section{Etymology}

The name of the new species is derived from the host plant genus Grindelia.

\section{Material examined}

\section{Holotype}

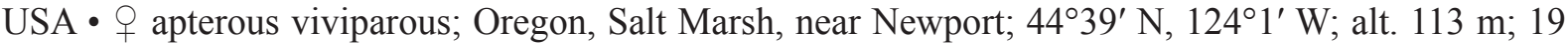
Apr. 1980; Hille Ris Lambers leg.; Grindelia stricta (= G. hirsutula); NHMUK 010121473.

\section{Paratypes}

USA $\bullet 1+q$ alate viviparous; same collection data as for holotype; NHMUK $010121473 \cdot 2+q+q$ apterous, 2 우우 alate viviparous; same collection data as for holotype; NHMUK $010121465 \bullet 1$ 우 apterous viviparous, 1 q alate viviparous; same collection data as for holotype; NHMUK 010121476 • 1 q apterous viviparous, 1 q alate viviparous; same collection data as for holotype; NHMUK 010121478 - 1 q apterous viviparous, 1 q alate viviparous; same collection data as for holotype; NHMUK $010121474 \cdot 1+$ apterous viviparous, 1 \& alate viviparous; same collection data as for holotype;

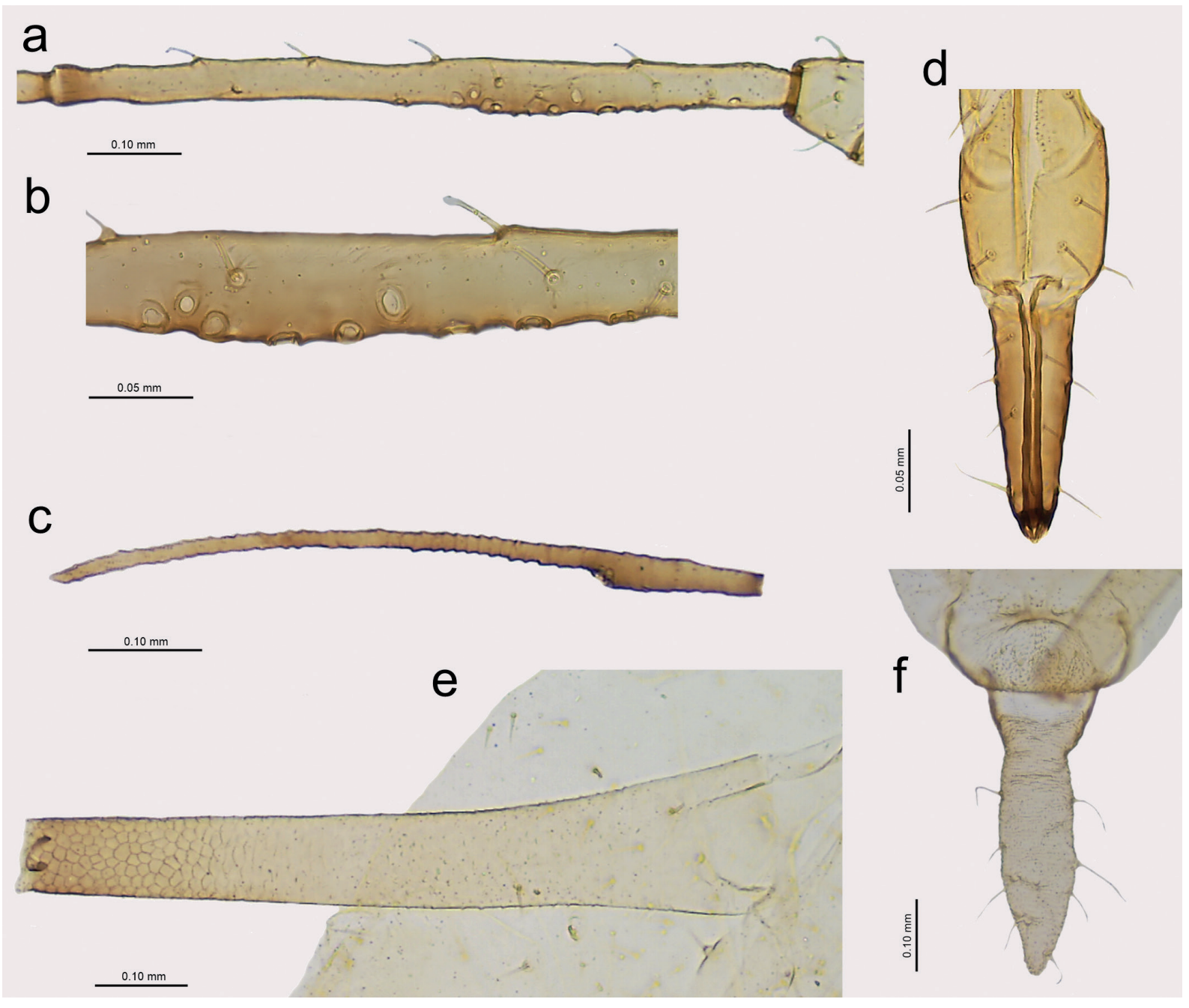

Fig. 3. Uroleucon (Lambersius) grindeliae sp. nov., paratype, apterous viviparous female (NHMUK 010121474). a. ANT III. b. Secondary rhinaria on ANT III. c. ANT VI. d. Ultimate rostral (III-V) segments. e. Siphunculus. f. Cauda. 
NHMUK $010121475 \cdot 1 q$ apterous viviparous, $1 \propto$ alate viviparous; same collection data as for holotype; NHMUK $010121477 \cdot 3 q q$ apterous viviparous, $2+q$ alate viviparous; same collection data as for holotype; DZUS $010121479 \bullet 1 q$ apterous, $1 q$ alate viviparous; same collection data as for holotype; NHMUK 010121480.

\section{Description}

Apterous viviparous female $(n=12)$

COLOR IN LIFE. Unknown.

Pigmentation of CLEAREd SPECimens on SLide. Body generally yellow to pale brown; ANT yellow with light brown ANT III (very basal part pale) or ANT yellow with darker apices of ANT III-V; coxae and trochanters pale; femora of legs yellow with very distal part light brown or uniformly yellow; tibiae yellow to light brown with slightly darker distal ends; tarsi light brown; SIPH pale to yellow with darker distal half; cauda pale (Fig. 1b).

Morphometric CHARACTERS. HW $0.20-0.25 \times$ ANT. Head with thick, rigid setae with flat or narrowly capitate apices, $0.035-0.049 \mathrm{~mm}$ long. ANT tubercles each with 3 setae. ANT $0.82-0.96 \times$ BL. ANT III with 7-16 rounded secondary rhinaria of different sizes with sclerotized rims (Fig. 3a-b), ANT IV longer than ANT V. PT 3.31-3.61 × BASE (Fig. 3c). Other antennal ratios: VI:III 0.90-1.18, V:III 0.570.66, IV:III 0.65-0.72, PT:III 0.70-0.92, PT:IV 1.07-1.35 and PT:V 1.22-1.35. ANT chaetotaxy: ANT bearing thick, rigid setae with blunt or narrow capitate apices. ANT III setae $0.020-0.042 \mathrm{~mm}$ long, LS ANT III 1.00-1.20 × BD III. ANT I with 4-6, ANT II with 3-4, ANT III with 12-15, ANT IV with 6-10 and ANT V with 5-8 setae. ANT VI with 3-4 basal, 3-4 apical and 3-5 setae on PT. Rostrum reaching hind coxae. URS $0.22-0.31 \times$ ANT III, $0.23-0.30 \times$ ANT VI, $0.29-0.38 \times$ PT, $1.03-1.37 \times$ BASE and 1.19-1.37 $\times$ HT II with 6-9 short, fine, pointed accessory setae (Fig. 3d). Mesosternal furca fused, wide, T-shaped. Hind femora bearing medium length, thick, rigid setae with narrow capitate or slightly pointed setae, $0.020-0.040 \mathrm{~mm}$ long. Hind tibiae bearing thick, rigid setae with mostly slightly pointed or blunt, shorter than width of tibiae, $0.025-0.050 \mathrm{~mm}$ long. HT I with 5:5:5 setae, HT II 0.18-0.23 $\times$ ANT III, $0.18-0.21 \times$ ANT VI, $0.23-0.27 \times$ PT and $0.80-1.00 \times$ BASE. SIPH subcylindrical, slightly tapering, straight with distinct zone of subapical reticulation and without a flange (Fig. 3e). Reticulated zone $0.27-$ $0.31 \times$ SIPH. SIPH $1.37-1.77 \times$ cauda, $0.24-0.30 \times$ BL and $1.08-1.33 \times$ ANT III. Abdomen membranous with medium length, thick rigid setae with narrowly capitate or blunt apices, $0.035-0.045 \mathrm{~mm}$ long on ABD I-V and 0.035-0.050 mm long on ABD VI-VIII. ABD VIII with 4 setae. Scleroites on setal bases absent on ABD I-V, while setae on ABD VI-VIII arising from very poorly visible, rounded and pale scleroites. Genital plate with two anterior setae longer than others, 7-10 posterior setae. Cauda tongueshaped with evident constriction near base, $1.55-2.52 \times$ its width at base and $0.14-0.19 \times \mathrm{BL}$, with 9-12 long and fine setae (Fig. 3f).

\section{Alate viviparous female $(\mathrm{n}=\mathbf{1 1})$ \\ COLOR IN LIFE. Unknown.}

Pigmentation OF CLEARED SPECIMENS ON SLIDE. Head and thorax slightly sclerotized, pale to pale yellow; ANT yellow with light brown ANT III (except base) and brown basal part of ANT IV; coxae and trochanters pale; femora of legs yellow with very distal ends light; tibiae brown with paler middle section; tarsi yellow to light brown; SIPH yellow to brown with paler bases; cauda pale (Fig. 1c).

Morphometric CHARACTERs. HW $0.18-0.20 \times$ ANT. Head with thick rigid setae with blunt or narrow capitate apices, $0.020-0.035 \mathrm{~mm}$ long. ANT tubercles each with $2-4$ setae. ANT $0.81-1.13 \times \mathrm{BL}$. ANT III with 20-26 rounded secondary rhinaria of different sizes with sclerotized rims, ANT IV longer than ANT V. PT 3.33-3.83× BASE. Other antennal ratios: VI:III 0.89-1.09, V:III 0.62-0.68, IV:III 0.65- 
0.76, PT:III 0.70-0.84, PT:IV 1.06-1.11 and PT:V 1.09-1.22. ANT bearing medium length thick and rigid setae with blunt or narrowly capitate apices. ANT III setae $0.020-0.040 \mathrm{~mm}$ long, LS ANT III $0.94-1.33 \times$ BD III. ANT I with 5-6, ANT II with 3-4, ANT III with 12-16, ANT IV with 7-10, ANT V with 7-8 setae. ANT VI with 3-4 basal, 4-5 apical and 3-4 setae on PT. Rostrum reaching mesosternum. URS $0.23-0.26 \times$ ANT III, $0.23-0.28 \times$ ANT VI, $0.31-0.35 \times$ PT, 1.03-1.37 $\times$ BASE and 1.29-1.41 $\times$ HT II with 7-9 fine-pointed accessory setae. Hind femora bearing medium length, thick rigid setae with narrowly capitate or slightly pointed setae, $0.020-0.037 \mathrm{~mm}$ long. Hind tibiae bearing thick, rigid setae with most slightly pointed or blunt, shorter than width of tibiae, $0.025-0.050 \mathrm{~mm}$ long. HT I with 5:5:5 setae, HT II $0.17-0.19 \times$ ANT III, $0.18-0.20 \times$ ANT VI, $0.23-0.25 \times$ PT and $0.78-0.97 \times$ BASE. SIPH subcylindrical, slightly tapering, straight with distinct zone of subapical reticulation and without a flange. Reticulated zone $0.32-0.40 \times \mathrm{SIPH}$. SIPH $1.55-1.71 \times$ cauda, $0.22-0.29 \times \mathrm{BL}$ and 0.89 $1.00 \times$ ANT III. Abdomen membranous with medium length thick, rigid setae with narrowly capitate or blunt apices, $0.025-0.045 \mathrm{~mm}$ long on ABD I-V and 0.030-0.052 mm long on ABD VI-VIII. ABD VIII with 4 setae. Scleroites on setal bases absent on ABD I-V, while setae on ABD VI-VII arising from very poorly visible, rounded scleroites. Genital plate with two anterior setae longer than others, 8-10 posterior setae. Cauda tongue-shaped with evident constriction near base, 1.95-2.92 $\times$ its width at base and $0.12-0.18 \times$ BL with $9-12$ long, fine setae.

\section{Remarks}

Of the six Grindelia-feeding aphids of Uroleucon, only U. penderum, U. robinsoni sp. nov. and $U$. grindeliae sp. nov. have shared characters: (1) ANT III has the majority of the secondary rhinaria on the basal half, (2) their URS/HT II ratio is 1.15 or more and (3) the coxae and trochanters are pale (Robinson 1986; Blackman \& Eastop 2020).

The apterous viviparous females of $U$. grindeliae sp. nov. differ from the same morphs of $U$. penderum and $U$. robinsoni $\mathrm{sp}$. nov. in the following characters: (1) their ANT PT/BASE ratio is 3.31-3.58 in $U$. grindeliae, while it is 3.6-6.5 in U. penderum and U. robinsoni and (2) their ANT PT/CAUDA ratio is 1.00-1.20 in U. grindeliae, while it is 1.5-2.0 in U. penderum and U. robinsoni (Blackman \& Eastop 2020).

\section{Biology and distribution}

Representatives of this species live on Grindelia hirsutula in Oregon, USA. Other morphs and the life cycle of the new species are unknown.

\section{Discussion}

The subgenus Lambersius is a Nearctic group of yellowish-green or green aphids that have a pale cauda and dark siphunculi with pale or almost pale bases or completely pale siphunculi (Robinson 1986; Heie 1995; Nieto Nafría et al. 2007). Robinson (1986) prepared an annotated list of the species of Lambersius that are known north of Mexico in North America, provided a key for 29 species and described seven new taxa. At present, 26 species of the subgenus Lambersius have been reported from the USA (Blackman \& Eastop 2020).

There are six species of Uroleucon living on Grindelia spp. in North and South America: Uroleucon (Uroleucon) brevisiphon de Carvalho, 1998 on Baccharis L. spp. and Grindelia sp. in Chile; Uroleucon (Uroleucon) chani Robinson, 1985 on Grindelia hirsutula and Gnaphalium L. sp. in Canada and Mexico; oligophagous Uroleucon (Lambersius) erigeronense (Thomas, 1878) on Grindelia in the USA; Uroleucon (Lambersius) payuniense Ortego \& Nieto Nafría, 2007 on Grindelia chiloensis (Cornel.) Cabrera in Argentina; Uroleucon (Lambersius) penderum on Grindelia integrifolia DC., Grindelia sp. and Heterotheca inuloides Cass. in Canada, the USA and Mexico and Uroleucon (Lambersius) richardsi 
(Robinson, 1964) on Grindelia spp. and Viguiera Kunth sp. in Canada, the USA and Mexico (Robinson 1964, 1985, 1986; Nieto Nafría et al. 2007, 2011, 2019; Jensen et al. 2010; Blackman \& Eastop 2020).

The apterous viviparous females of $U$. brevisiphon and $U$. chani have a completely dark SIPH and pale cauda and belong to the subgenus Uroleucon, while the remaining four species have dark siphunculi with pale or almost pale bases or completely pale siphunculi, pale coxae and trochanters and belong to the subgenus Lambersius. Uroleucon brevisiphon is listed in square brackets in the list of Grindeliaassociated aphids as a dubious record (Blackman \& Eastop 2020). Two Grindelia-feeding species fit the diagnosis of the genus Uroleucon well and are members of the genus Lambersius based on the pigmentation of the siphunculi, coxae and trochanters. After our investigation, the number of species of Lambersius increased from 53 to 55 species. It would be interesting to conduct combined morphological, morphometric and molecular (DNA barcoding) investigations of species of the subgenus Lambersius in the future.

\section{Key to the apterae of Uroleucon on Grindelia spp.}

Note: the key is modified from that of Blackman \& Eastop (2020)

7. SIPH entirely dark Uroleucon chani Robinson, 1985

- SIPH pale, at least on basal part (Figs 2e, 3e)

8. ANT III with $12-31$ rhinaria extending to $0.80-0.98$ from base with majority on distal half

Uroleucon richardsi (Robinson, 1964)

- ANT III with 5-26 rhinaria extending to 0.4-0.8 from base with majority on the basal half (Figs 2a, 3a)

9 R IV+V 0.9-1.2 $\times$ HT II, with $6-10$ accessory hairs. SIPH $1.85-2.5 \times$ cauda. ANT PT/BASE $3.2-$ 5.7

- $\mathrm{R}$ IV+V 1.15-1.5 $\times$ HT II with 7-13 accessory hairs (Figs 2d, 3d). SIPH 1.5-2.6 × cauda. ANT PT/ BASE 3.0-5.2

10. Siphunculi pale at base, dark over most of their length. Distal caudal hairs usually short and blunt or capitate. Dorsal cephalic hairs $18-35 \mu \mathrm{m}$ long ..... Uroleucon erigeronense (Thomas, 1878)

- Siphunculi pale. Distal caudal hairs pointed. Dorsal cephalic hairs 45-55 $\mu \mathrm{m}$ long

Uroleucon payuniense Ortego \& Nieto Nafría, 2007

11. ANT PT/BASE 3.31-3.58. ANT PT 1.0-1.2 × cauda .. Uroleucon (Lambersius) grindeliae sp. nov.

- $\quad$ ANT PT/BASE 3.6-5.2. ANT PT 1.5-2.0 × cauda 12

12. SIPH 2.30-2.68 $\times$ cauda. R IV+V 1.18-1.25 $\times$ HT II. Tibiae dusky/dark for most of their length (Fig. 1a) Uroleucon (Lambersius) robinsoni sp. nov.

- SIPH 1.65-1.95 × cauda. R IV+V 1.3-1.6× HT II. Tibiae pale except at apices Uroleucon penderum Robinson, 1986

\section{Acknowledgments}

We are sincerely grateful to Paul A. Brown and David Ouvrard (NHMUK, London, UK) for their kind assistance and support during our visits to the collection as well as for the loan of the material. Special thanks go to Eric Maw (Agriculture and Agri-Food Canada, Ottawa, Canada) and Andrew S. Jensen (California Academy of Sciences, San Francisco, CA, USA) for the linguistic assistance and comments on the manuscript. We would like to thank the editor and two reviewers for their valuable comments and suggestions, which helped the authors to improve the first version of the manuscript. Mariusz Kanturski 
gratefully acknowledges the Scholarship for Outstanding Young Scientists from the Ministry of Science and Higher Education of Poland (1165/E-340/STYP/12/17).

\section{References}

Blackman R.L. \& Eastop V.F. 2006. Aphids on the World's Herbaceous Plants and Shrubs. John Wiley and Sons, London.

Blackman R.L. 2010. Aphids - Aphidinae (Macrosiphini). Handbooks for the Identification of British Insects 2 (7). Royal Entomological Society, St Albans.

Blackman R.L. \& Eastop V.F. 2020. Aphids of the World's Plants: An Online Identification and Information Guide. Available from http://www.aphidsonworldsplants.info [accessed 15 Mar. 2020].

Favret C. 2020. Aphid Species File. Version 5.0/5.0. Available from http://Aphid.SpeciesFile.org [accessed 15 Mar. 2020].

Heie O.E. 1995. The Aphidoidea of Fennoscandia and Denmark VI. Aphidinae. Part 3 of Macrosiphini and Lachnidae. Fauna Entomologica Scandinavica 31: 1-222.

Ilharco F.A. \& van Harten A. 1987. Systematics. In: Minks A.K. \& Harrewijn P (eds) Aphids: their Biology, Natural Enemies and Control: 51-77. Elsevier Science Publishers, Amsterdam.

Jensen A.S., Miller G.L. \& Carmichael A. 2010. Host range and biology of Uroleucon (Lambersius) erigeronense (Thomas, 1878), and its synonymy with Uroleucon (Lambersius) escalantii (Knowlton) 1928 (Hemiptera: Aphididae). Proceedings of the Entomological Society of Washington 112 (2): 239245. https://doi.org/10.4289/0013-8797-112.2.239

Nieto Nafría J.M., Mier Durante M.P., Ortego J. \& Seco Fernández M.V. 2007. The genus Uroleucon (Hemiptera: Aphididae: Macrosiphini) in Argentina, with descriptions of five new species. The Canadian Entomologist 139 (2): 154-178. https://doi.org/10.4039/n05-100

Nieto Nafría J.M., Mier Durante M.P. \& Pérez Hidalgo N. 2011. Mexican Uroleucon (Hemiptera: Aphididae) from the collection of the Muséum national d'Histoire naturelle of Paris with eleven new species. Florida Entomologist 94 (3): 622-648. https://doi.org/10.1653/024.094.0329

Nieto Nafría J.M., von Dohlen C.D., Moreno-González V., Ortego J. \& Mier Durante M.P. 2019. The species of Uroleucon (Hemiptera: Aphididae) living on Adesmia (Fabaceae) in Argentina, with the description of a new species. Zootaxa 4555 (4): 561-572. https://doi.org/10.11646/zootaxa.4555.4.7

Robinson A.G. 1964. A new species of Dactynotus Rafinesque (Homoptera: Aphididae) from Grindelia squarrosa (Pursh) Dunal. The Canadian Entomologist 96 (10): 1330-1332. https://doi.org/10.4039/Ent961330-10

Robinson A.G. 1985. Annotated list of Uroleucon (Uroleucon, Uromelan, Satula) (Homoptera: Aphididae) of America north of Mexico, with keys and descriptions of new species. The Canadian Entomologist 117 (8): 1029-1054. https://doi.org/10.4039/Ent1171029-8

Robinson A.G. 1986. Annotated list of Uroleucon (Lambersius) (Homoptera: Aphididae) of America north of Mexico, with a key and descriptions of new species. The Canadian Entomologist 118 (6): 559-576. https://doi.org/10.4039/Ent118559-6

The Plant List. 2013. Version 1.1. Available from http://www.theplantlist.org/ [accessed 1 Mar. 2020)]. 
Manuscript received: 29 April 2020

Manuscript accepted: 14 October 2020

Published on: 16 December 2020

Topic editor: Nesrine Akkari

Section editor: Anna Namyatova

Desk editor: Eva-Maria Levermann

Printed versions of all papers are also deposited in the libraries of the institutes that are members of the EJT consortium: Muséum national d'histoire naturelle, Paris, France; Meise Botanic Garden, Belgium; Royal Museum for Central Africa, Tervuren, Belgium; Royal Belgian Institute of Natural Sciences, Brussels, Belgium; Natural History Museum of Denmark, Copenhagen, Denmark; Naturalis Biodiversity Center, Leiden, the Netherlands; Museo Nacional de Ciencias Naturales-CSIC, Madrid, Spain; Real Jardín Botánico de Madrid CSIC, Spain; Zoological Research Museum Alexander Koenig, Bonn, Germany; National Museum, Prague, Czech Republic. 